Supporting Information -

\title{
Merocyanines in a halogen bonded network involving inorganic building blocks
}

Vanessa K. Seiler $^{a}$, Nikolay Tumanov $^{b}$, Koen Robeyns $^{a}$, Benoit Champagne ${ }^{b}$, Johan Wouters $^{b}$ and Tom Leyssens ${ }^{a *}$

aMCN Institute of Condensed Matter and Nanosciences, Université catholique de Louvain, Place Louis Pasteur 1, 1348 Louvain-la-Neuve (Belgium). E-mail: tom.leyssens@uclouvain.be

${ }^{\mathrm{b}}$ Chemistry Department, University of Namur, Rue de Bruxelles 61, 5000 Namur (Belgium) 


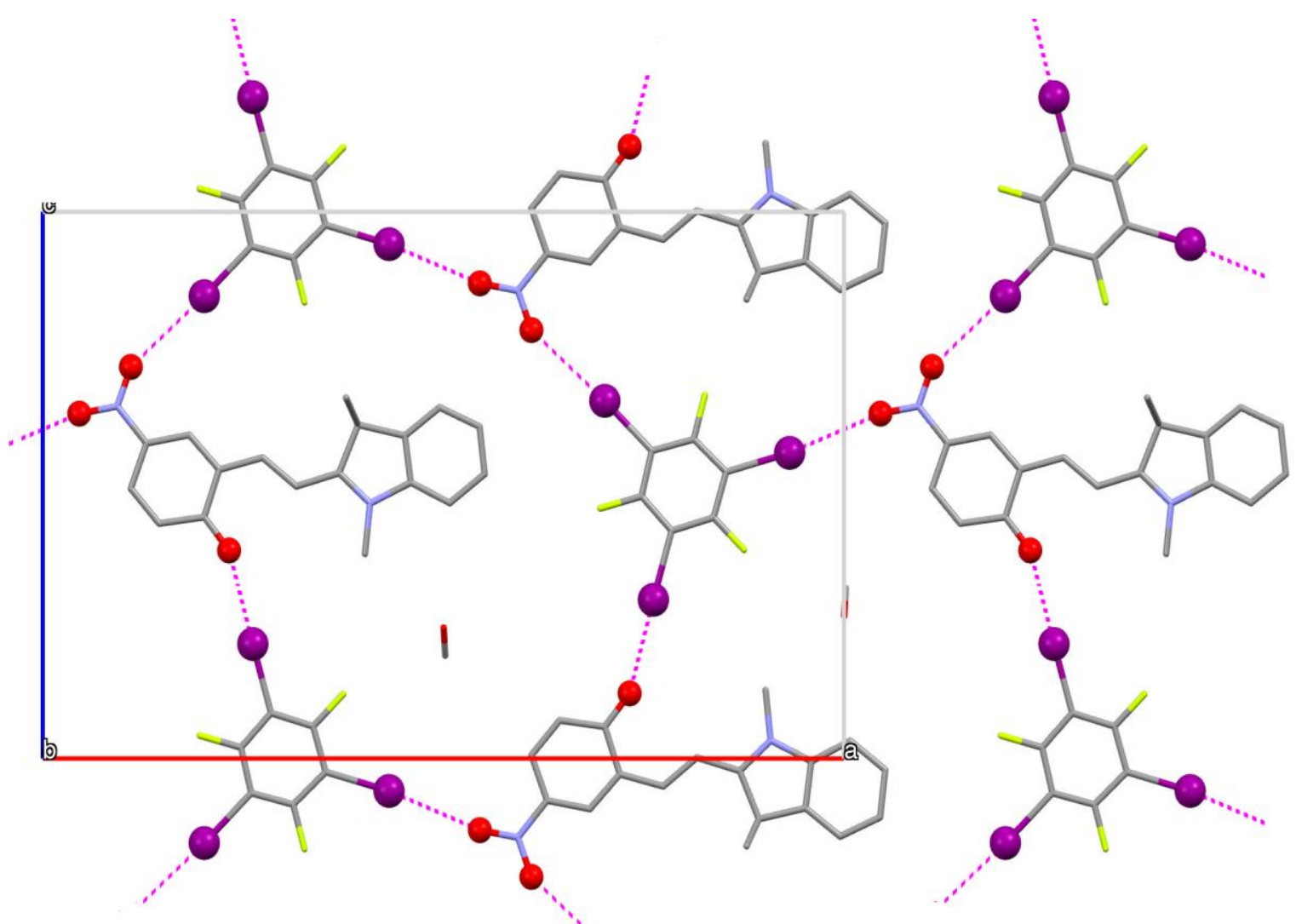

Figure S1: Partial packing diagram of (Ia'). Halogen bonds are indicated by the purple dashed lines.

Table S1: Composition of the crystallization experiments for slow solvent evaporation.

\begin{tabular}{|c|c|}
\hline Crystal & Description \\
\hline (la) & $5.78 \mathrm{mg}$ SPNO2 and $7.96 \mathrm{mg}$ 135tfib were dissolved in $0.5 \mathrm{~mL}$ MeCN. \\
\hline$($ (la') & $5.61 \mathrm{mg}$ SPNO2 and $8.42 \mathrm{mg}$ 135tfib were dissolved in $2 \mathrm{~mL} \mathrm{MeOH.}$ \\
\hline (Ib) & $10.00 \mathrm{mg}$ SPNO2 were dissolved in $2 \mathrm{~mL}$ EtOH and $4.7 \mu \mathrm{L} 13 \mathrm{tfib}$ were added. \\
\hline (II) & $\begin{array}{l}9.63 \mathrm{mg} \mathrm{SPH} \text { were dissolved in } 0.5 \mathrm{~mL} \text { acetone, } 4.85 \mu \mathrm{L} 14 \mathrm{tfe} \text { and } 2.98 \mu \mathrm{L} \mathrm{HCl} \\
\text { were added. }\end{array}$ \\
\hline (Illa) & $\begin{array}{l}5.12 \mathrm{mg} \mathrm{SPH} \text { and } 4.81 \mathrm{mg} 135 \mathrm{tfib} \text { were dissolved in } 1 \mathrm{~mL} \mathrm{EtOH} \text { and } 2.98 \mu \mathrm{L} \mathrm{HCl} \\
\text { were added. }\end{array}$ \\
\hline (IIb) & $\begin{array}{l}4.96 \mathrm{mg} \mathrm{SPH} \text { and } 8.10 \mathrm{mg} 14 \mathrm{tfib} \text { were dissolved in } 0.6 \mathrm{~mL} \text { acetone and } 2.98 \mu \mathrm{L} \\
\mathrm{HCl} \text { were added. }\end{array}$ \\
\hline (IIC) & $\begin{array}{l}10.61 \mathrm{mg} \text { SPH and } 11.77 \mathrm{mg} 14 \mathrm{tfbb} \text { were dissolved in } 0.5 \mathrm{~mL} \text { acetone and } 2.98 \\
\mu \mathrm{L} \mathrm{HCl} \text { were added. }\end{array}$ \\
\hline (IIIla) & $\begin{array}{l}10.01 \mathrm{mg} \text { SPBenz, approx. } 5 \mathrm{mg} \mathrm{ZnCl}_{2} \text { and } 9.30 \mathrm{mg} 14 \mathrm{tfbb} \text { were dissolved in } 0.5 \\
\mathrm{~mL} \text { acetone. }\end{array}$ \\
\hline (IIIb) & $\begin{array}{l}5.28 \mathrm{mg} \text { SPBenz, } 7.73 \mathrm{mg} 135 \mathrm{tfib} \text { and } 4.00 \mathrm{mg} \mathrm{CoCl} 2 \cdot 6 \mathrm{H}_{2} \mathrm{O} \text { were dissolved in } 1.3 \\
\text { mL MeCN. }\end{array}$ \\
\hline
\end{tabular}




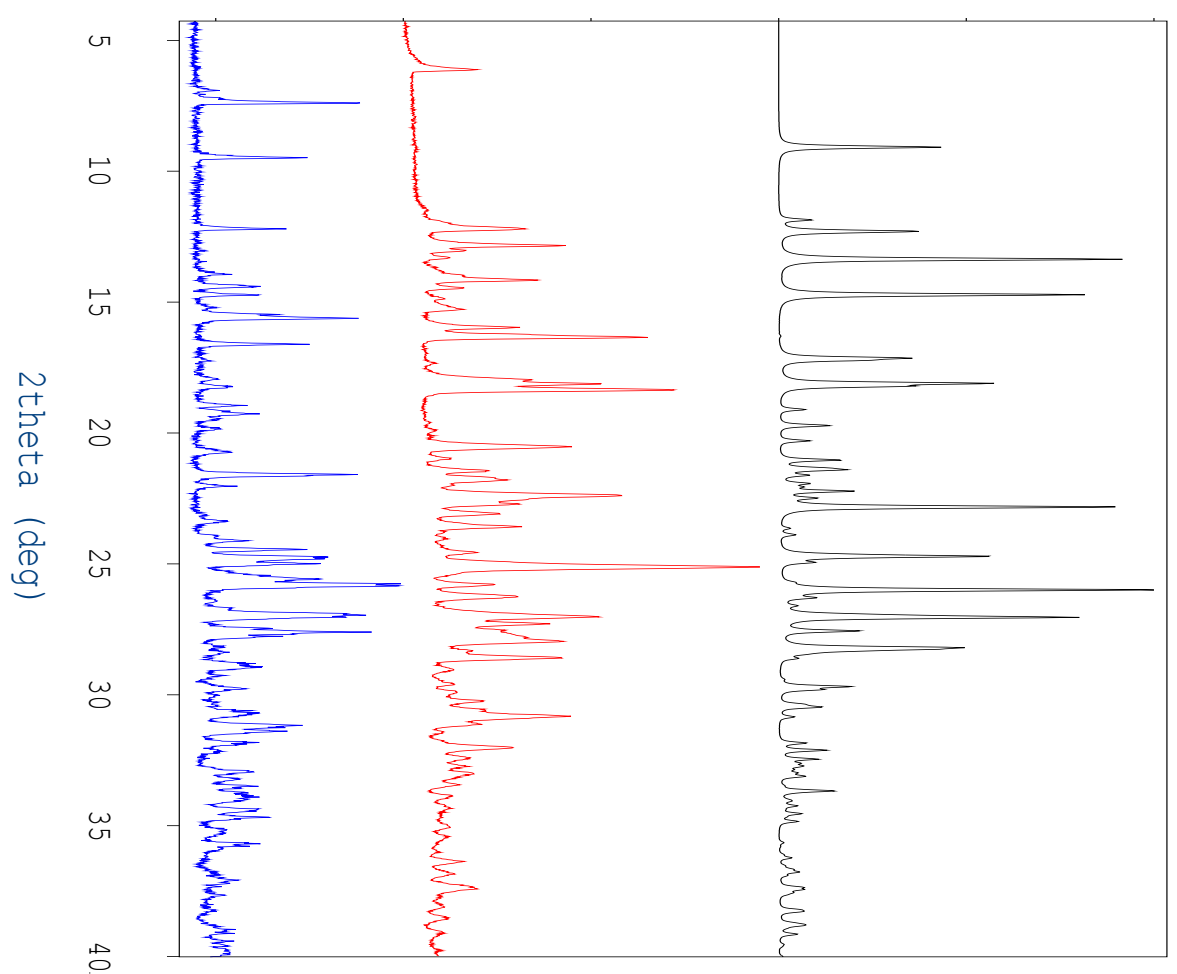

Figure S2: XRPDs of the from LAG obtained new solid forms of $\mathrm{MCHH}^{+} \mathrm{Cl}^{-}$with $12 \mathrm{tfib}$ (blue curve) and 12 tfe (red curve) compared to the XRPD patterns calculated from single crystal data of $\mathrm{MCHH}^{+} \mathrm{Cl}^{-}$(black curve).

\section{Structural details of (II)}

Single crystals of (II) suitable for analysis were obtained from crystallization experiments of SPH with $12 \mathrm{tfe}$ and $\mathrm{HCl}$ in acetone. Instead of the halogen bonded form of the spiropyran with the XB donor, the presence of a new polymorph of $\mathrm{MCHH}^{+} \mathrm{Cl}^{-}$(II) had been confirmed. (II) can be transformed in a slurry of acetone within few hours to the more stable form under ambient conditions. It crystallizes in the space group $\mathrm{Cmca}$ with a $\mathrm{MCHH}^{+} \mathrm{Cl}^{-}$molecule on a special position in the asymmetric unit (Figure S3). The layer like arrangement differs from the previous stated polymorph in the space group $P 2_{1} / n$ being the originate for the different color property of orange and yellow material. 


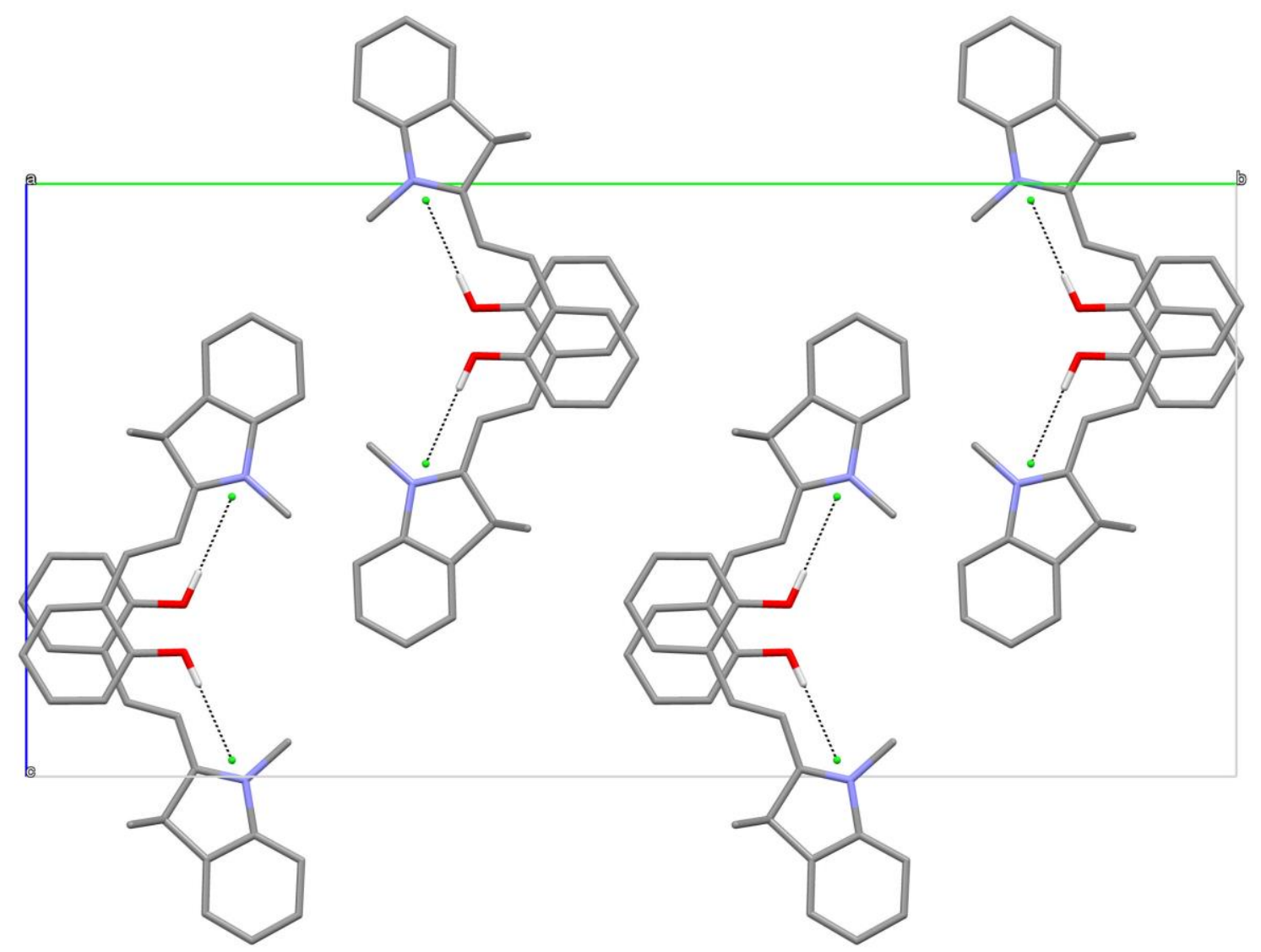

Figure S3: Partial packing diagram of (II). Hydrogen bonds are indicated as black dashed lines.

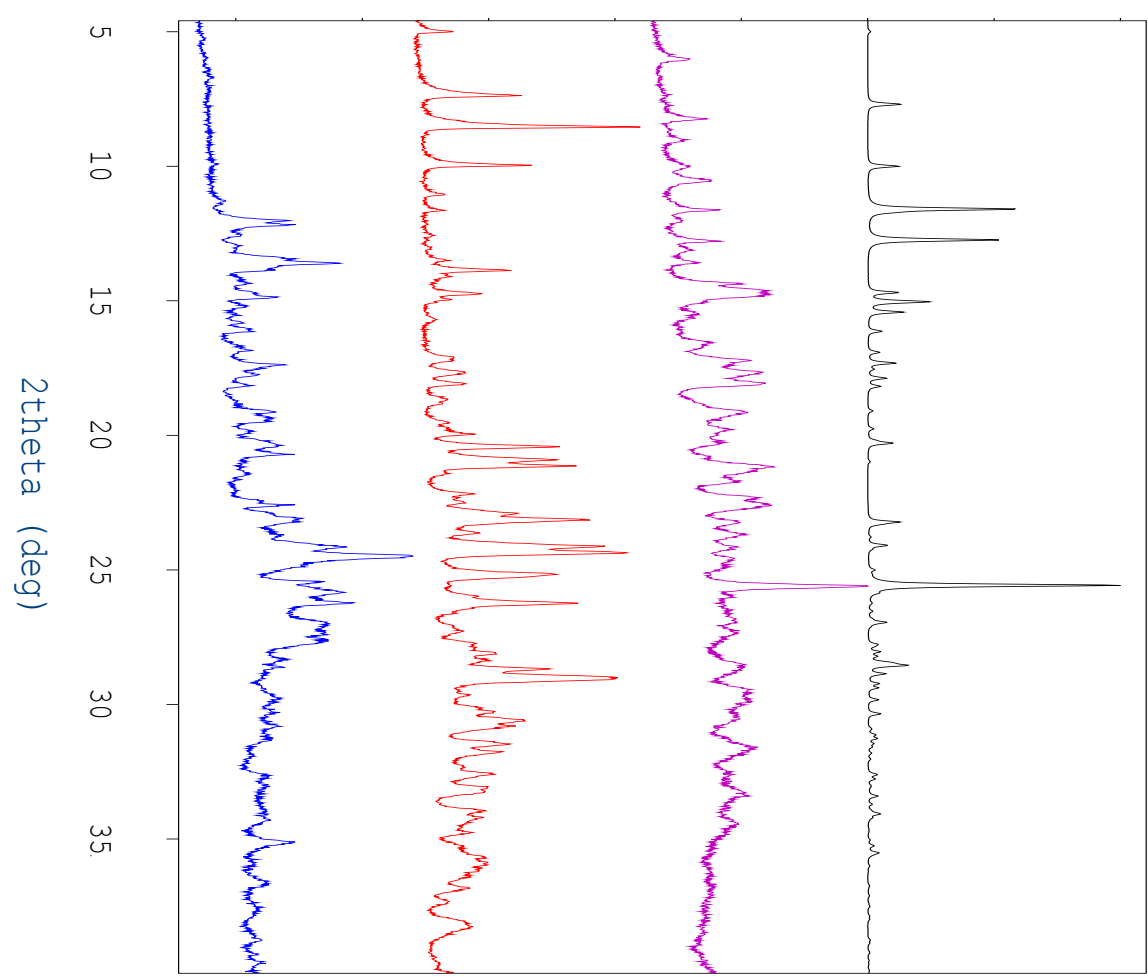

Figure S4: XRPDs of the from LAG obtained new solid forms of $\mathrm{MCBenz}^{+} \mathrm{Cl}^{-}$with $14 \mathrm{tfib}$ (blue curve), 12tfib (red curve) and 12tfe (purple curve) compared to the XRPD patterns calculated from single crystal data of $\mathrm{MCBenzH}^{+} \mathrm{Cl}^{-}$(black curve). 


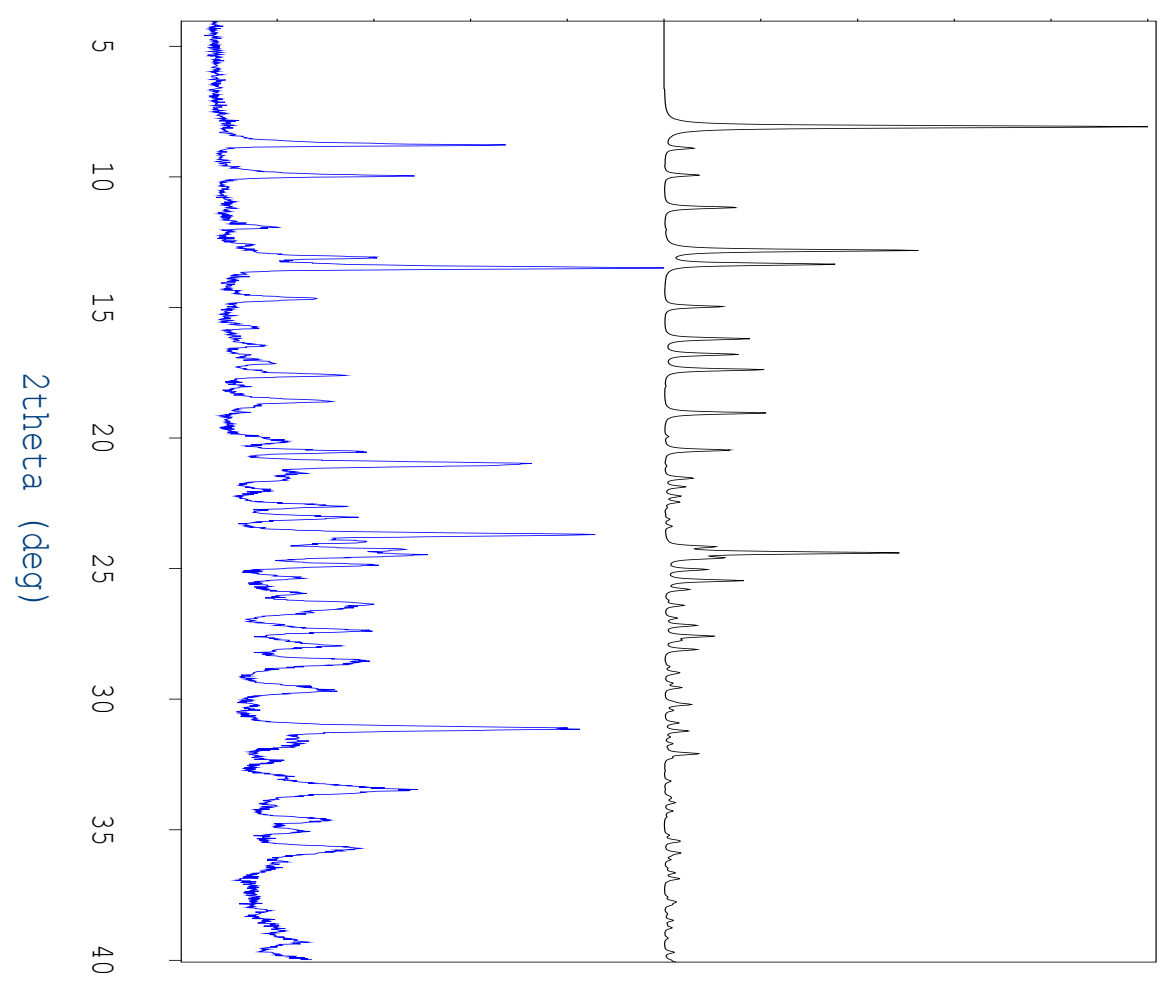

Figure S5: XRPDs of the from LAG obtained new solid form of $\mathrm{MCBenzZnCl}_{2}$ with 12 tfe (blue curve) compared to the XRPD patterns calculated from single crystal data of the acetone solvate MCBenzZnCl 2 (black curve).

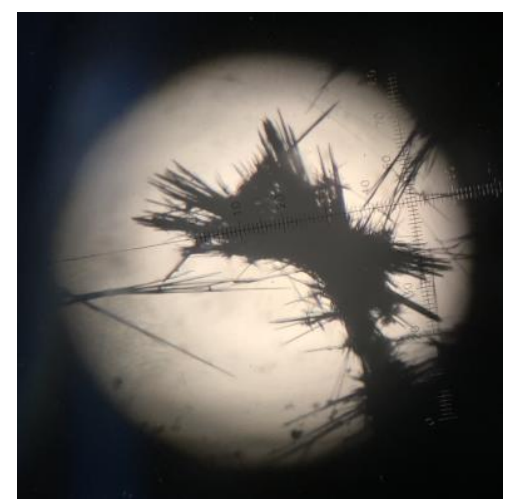

Figure S6: Picture of the single crystal of (Ib) used for single crystal XRD measurement. 
Table S2: Halogen bond $(C-X \cdots A / X)$, overview bond lengths and angles.

\begin{tabular}{|c|c|c|c|c|c|}
\hline & $C-X \cdots A$ & $d(X \cdots A)[\AA]$ & $\Delta \mathrm{vdWr}[\AA]^{*}$ & $\begin{array}{l}\text { Reduction } \\
\text { ratio }\end{array}$ & $\Varangle(C-X \cdots A)\left[{ }^{\circ}\right]$ \\
\hline \multirow[t]{3}{*}{ (la) } & C1B-I11B' O1A & $2.789(8)$ & -0.71 & 0.80 & $176.0(3)$ \\
\hline & 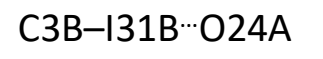 & 3.165 (10) & -0.34 & 0.90 & $176.8(3)$ \\
\hline & 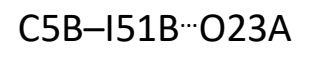 & 3.355 (10) & -0.15 & 0.96 & $161.0(3)$ \\
\hline \multirow[t]{3}{*}{$\left(I a^{\prime}\right)$} & C5B-151B $\cdots 1 A$ & $2.831(3)$ & -0.67 & 0.81 & $179.44(16)$ \\
\hline & 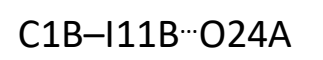 & $3.102(5)$ & -0.40 & 0.89 & $177.19(16)$ \\
\hline & 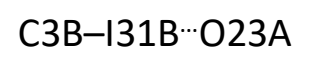 & $3.087(5)$ & -0.41 & 0.88 & $173.7(2)$ \\
\hline \multirow[t]{4}{*}{ (Ib) } & C1B-I11B”O1A & $2.806(8)$ & -0.69 & 0.80 & $176.6(4)$ \\
\hline & C3C-I11C‥ $024 \mathrm{~A}$ & $3.090(14)$ & -0.41 & 0.88 & $151.6(4)$ \\
\hline & C1C-I11C‥023A & $3.333(13)$ & -0.17 & 0.95 & $170.1(3)$ \\
\hline & C3B-131B $\cdots 24 A$ & 3.059 (13) & -0.44 & 0.87 & $175.1(4)$ \\
\hline (Illa) & C1B-I11B $\cdots \mathrm{Cl}$ & $3.2152(12)$ & -0.51 & 0.86 & $169.84(12)$ \\
\hline (IIb) & 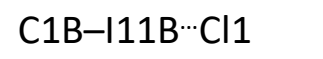 & $3.1399(12)$ & -0.59 & 0.84 & $173.30(11)$ \\
\hline (IIC) & $\mathrm{C} 1 \mathrm{~B}-\mathrm{Br} 11 \mathrm{~B} \cdots \mathrm{Cl} 1$ & 3.1695 (15) & -0.43 & 0.89 & $174.37(16)$ \\
\hline (IIla) & $\mathrm{C} 1 \mathrm{~B}-\mathrm{Br} 11 \mathrm{~B} \cdots \mathrm{Cl} 2 \mathrm{~A}$ & $3.2787(6)$ & -0.32 & 0.92 & $152.27(6)$ \\
\hline \multirow[t]{7}{*}{ (IIIb) } & C1D-I11D $\cdots \mathrm{Cl} 3 \mathrm{C}$ & $3.1799(14)$ & -0.55 & 0.85 & $169.13(14)$ \\
\hline & C1G-I11G $\cdots \mathrm{Cl} 4 \mathrm{C}$ & $3.2832(14)$ & -0.45 & 0.88 & $172.01(14)$ \\
\hline & $\mathrm{C} 1 \mathrm{E}-\mid 11 \mathrm{E} \cdots \mathrm{Cl} 4 \mathrm{C}$ & 3.4287 (14) & -0.30 & 0.92 & $173.11(15)$ \\
\hline & C3D-131D”Cl2C & $3.4524(14)$ & -0.28 & 0.92 & $152.08(13)$ \\
\hline & C3E-I31E $\cdots \mathrm{Cl} 5 \mathrm{C}$ & $3.5331(13)$ & -0.20 & 0.95 & $158.91(16)$ \\
\hline & C3G-131G $\cdots \mathrm{Cl} 5 \mathrm{C}$ & $3.5772(13)$ & -0.15 & 0.96 & $153.79(12)$ \\
\hline & C5E-I51E $\cdots \mathrm{Cl} 3 \mathrm{C}$ & 3.1874 (14) & -0.54 & 0.86 & $168.44(14)$ \\
\hline
\end{tabular}

*Van-der-Waals radii by A. Bondi, J. Phys. Chem. 1964, 3, 441. 